\title{
Dynamic Response of Saturated Sandy Foundation and Friction Pile under Seismic Action
}

\author{
Peisen Wang ${ }^{1,2,3}$, Hongyan Ding ${ }^{1,2}$, Puyang Zhang ${ }^{1,2}$, Ernian Zhao $^{3 *}$, Jialin Zhou ${ }^{4}$, Jihong Bai $^{5}$ \\ ${ }^{1}$ State Key Laboratory of Hydraulic Engineering Simulation and Safety, Tianjin University, Tianjin 300072, China \\ ${ }^{2}$ School of Civil Engineering, Tianjin University, Tianjin 300072, China \\ ${ }^{3}$ School of Civil Engineering, Shandong Jianzhu University, Jinan 250101, China \\ ${ }^{4}$ School of Engineering and Build Environment, Griffith University, 58 Parklands Dr, Southport, Queensland 4215, Australia \\ ${ }^{5}$ China State Railway Investment and Construction Group Co., Ltd, Beijing 100053, China
}

Corresponding Author Email: zhaoernian19@sdjzu.edu.cn

https://doi.org/10.18280/ijsse.100403

Received: 15 April 2020

Accepted: 29 June 2020

\section{Keywords:}

seismic action, saturated sandy foundation, friction pile, dynamic response

\begin{abstract}
Karst landform poses a great challenge to the deep foundation construction of bridges However, there is little report on the dynamic response of piles under seismic action in karst area. To make up for the gap, this paper mainly explores the pile-soil interaction of saturated sandy foundation under seismic effect. Taking friction pile and saturated sandy foundation as the objects, the authors carried out shaking table tests on how the waveform and peak acceleration of seismic waves affect pore pressure and acceleration response of the soil around the pile. Further, the peak strain distribution of the friction pile was investigated under different sandy foundation conditions. The results show that the pore pressure of saturated sand around the pile first increases rapidly, then stabilizes, and later declines slowly under seismic action; the peak acceleration of saturated sand is negatively correlated with vertical depth; the change of acceleration increases with the proximity to the pile; the earthquake has a dramatic impact on the pile surrounded by saturated sand, i.e. the saturated sandy foundation weakens the seismic resistance of the pile; the peak strain of friction pile is smaller in the middle and greater at the ends; under the same seismic wave, the strain response of the friction pile surrounded by saturated sand is greater than that of the pile surrounded by dry sand. The research results provide a good reference for deep foundation construction in karst area.
\end{abstract}

\section{INTRODUCTION}

The liquefaction of saturated sandy foundation is one of the main disasters that damage the pile foundation of bridge structure [1,2]. In 1976 Tangshan earthquake, 15 out of all 18 bridges in the afflicted area collapsed due to site liquefaction, resulting in structural damage (e.g. abutment and bank slip) and foundation failure. Many foundation piles were seriously damaged by the liquefaction of saturated sandy foundation during 1964 Niigata earthquake and 1999 Jiji earthquake. Many other examples of seismic damage on pile foundations are available in the literature [3-5].

Many scholars have probed deep into the mechanical behaviors of pile foundation under seismic action. Some focused on the single pile foundation, and some tackled pile group through shaking table tests [6-11]. Many researchers resorted to the centrifuge experiments $[12,13]$. For example, McVay et al. [14] conducted centrifuge tests on two pile groups $(3 \times 3$ and $7 \times 3)$, and observed that: the leading row suffered the maximum lateral loads; the middle piles were subject to smaller lateral load than side piles. Motamed et al. [15] extended the size of pile group to $11 \times 11$, and investigated how several parameters affect response of pile groups and the mechanism of later flow.

Numerical simulation provides an important tool to determine the dynamic response of soil-pile under seismic wave. Focusing on the soil-structure interaction under seismic action, the common methods for numerical simulation include substructure method, finite-element method, and hybrid method [16, 17]. With the aid of surface-to-surface contact element, Lu et al. [18] explored the nonlinearity state of the soil-pile interface, and selected an equivalent linear model to research the soil behavior. Chau et al. [19] explained the observed soil-pile system under dynamic wave through nonlinear finite-element analysis with a nonlinear gap element. Under seismic action, the soil around the pile might be liquified, complicating the dynamic response of the pile foundation. Due to the constraints of model hypothesis and parameters acquisition for soil constitutive relationship, it is difficult to reproduce the macro failure mode and dynamic response features of bridge pile foundation through the numerical simulation of the pile-soil-structure interaction in saturated sandy layer. Compared with numerical results, the experimental results are relatively trustworthy.

In karst landform, two types of pile foundations are often designed to adapt to the heavy presence of underground karst caves: the friction pile foundation and the end bearing dominated pile foundation. The friction pile foundation can be constructed over the karst cave, as its bearing capacity is fully resisted by the shaft. If the load is transferred from pile end, i.e. the pile is not purely a friction pile, it is vital to determine the distance from the pile top to the roof of the cave. This is because the bearing capacity of the pile foundation is mainly affected by distance [20]. The end bearing dominated pile 
foundation passes through the karst cave, reaching a very hard bearing stratum. Liquefaction is easy to occur in karst area, owing to the high groundwater table and the thick saturated sandy foundation in the surface. Therefore, it is an important engineering problem whether the bridge structure in karst area will be damaged by liquefaction in an earthquake.

This paper probes into the dynamic response of the friction pile foundation in karst landform through shaking table tests. The dynamic response of acceleration and pore pressure ratio was investigated under the waveforms of El Centro and Taft seismic waves. The main contributions of this research are as follows:

(1) Completing the liquefaction discrimination of saturated sandy foundation and related problems, introducing the foundation disasters caused by the liquefaction of saturated sandy foundation under seismic action;

(2) Clarifying the effect of seismic waveform on the pore pressure of saturated sand layer at various depths;

(3) Disclosing the acceleration response features of saturated sandy foundation under different seismic waves and peak acceleration conditions;

(4) Comparing the peak strain distributions of friction pile in different foundations.

\section{SHAKING TABLE TESTS}

\subsection{Test setup}

To disclose the seismic response of different soils and the pile structure in saturated sandy foundation, a suspended laminar shear box was designed for shaking table tests. With a size of $2,210 \times 1,510 \times 1,670 \mathrm{~mm}$, the box has sufficient inner space for pile-soil interaction.

The main components of the suspended laminar shear box include a suspension support, a bottom plate, and a model box. Specifically, the suspension support contains 8 steel columns around the soil box. The bottom plate combines section steel with steel plate. The model box encompasses 15 layers of light and rigid closed aluminum alloy frames, which are arranged vertically at an equal interval of $150 \mathrm{~mm}$. To limit the overall weight, the model box is lifted by 24 steel cables. The top of each steel cable is fixed on the steel beam. In addition, the suspended laminar shear box was lined with a layer of rubber aquiclude to prevent soil from leaking out. Figure 1 presents the three-dimensional (3D) design drawings and a photo of the suspended laminar shear box.

Next, two friction piles, denoted as FP-0 and FP-1, were prepared with polypropylene (elastic modulus: $1,500 \mathrm{MPa}$ ). Based on scale effect calculation, the sectional size and length of the two piles were determined as $200 \times 200 \mathrm{~mm}^{2}$ and $1,100 \mathrm{~mm}$, respectively.

As shown in Figure 2, the first pile FP-0 was installed to study the soil response under seismic action. Then, accelerometers and pore pressure gauges were deployed around FP- 0 . The vertical and the horizontal intervals between the accelerometers were $250 \mathrm{~mm}$ and $120 \mathrm{~mm}$, respectively. The pore pressure gauges were buried at the same locations of accelerometers. Located only $40 \mathrm{~mm}$ from the pile, these devices can capture representative data about soil-pile interaction. To measure strain data, a total of 8 strain gauges were arranged along one side of the second pile FP-1 with an equal interval of $100 \mathrm{~mm}$.
The piles were deployed at $740 \mathrm{~mm}$ away from the suspended laminar shear box. The distance is over 20 times of pile diameter, such that the box motions will not affect the dynamic responses of the piles.

Normally, shaking table tests can proceed after sand material is uniformly added to the suspended laminar shear box, for the measuring devices are all in place. However, two water injection steel pipes were installed at the bottom to saturate the sandy soil, because this research aims to disclose the seismic effect on saturated sandy foundation. It is believed that, when airless water is injected from the bottom, the air will be squeezed out from any void in the sandy soil. Once the water coming out from the surface becomes airless, the sandy soil must be fully saturated. The saturation process takes up to $36 \mathrm{~h}$ or more.
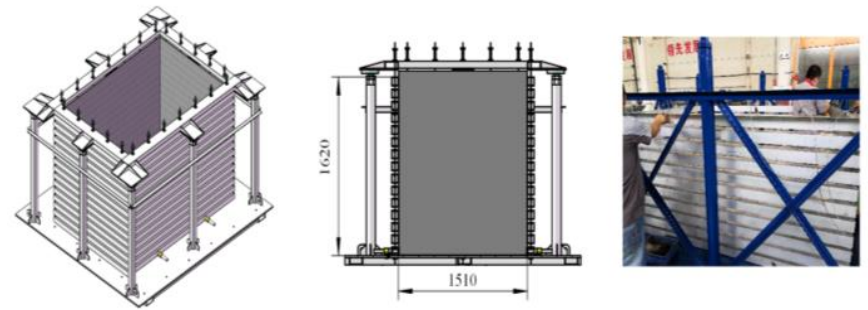

(a) 3D design model; (b) Longitudinal section; (c) Photo

Figure 1. The 3D design drawings and a photo of the suspended laminar shear box

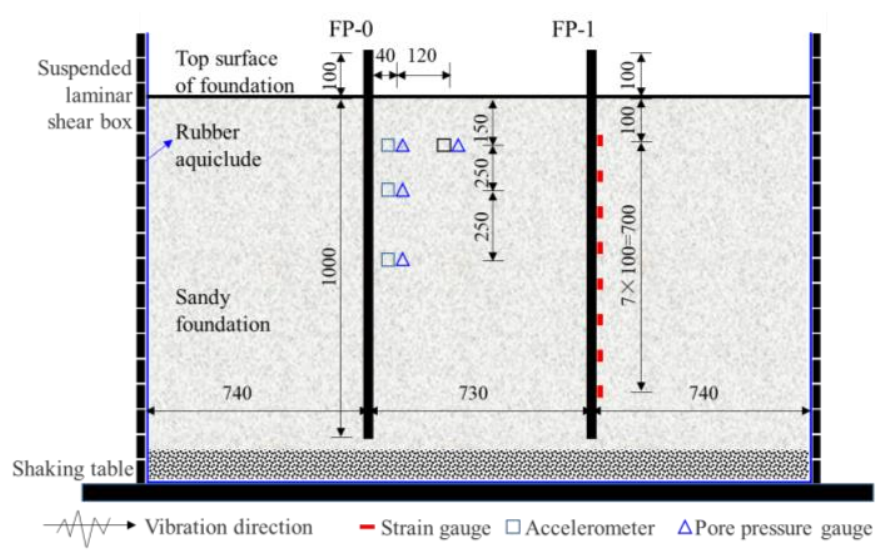

Figure 2. The arrangement of piles and measuring devices (not to scale)

\subsection{Test process and soil-pile reaction}

Considering the differences between seismic waves, two well-known seismic waves, namely, El Centro wave and Taft wave, were generated by a shaking table (size: $3 \mathrm{~m} \times 3 \mathrm{~m})$ installed beneath the suspended laminar shear box. Before applying either of the dynamic seismic waves, a cone penetration test (CPT) was performed to determine the dense state of sandy foundation.

The peak accelerations for time history analysis are available in the Code for Seismic Design of Buildings (GB 50011-2010). The peak accelerations for magnitude 7 frequent earthquake, magnitude 7 design earthquake, magnitude 7 rare earthquake, and magnitude 8 rare earthquake are $0.035 \mathrm{~g}, 0.1 \mathrm{~g}$, $0.22 \mathrm{~g}$, and $0.4 \mathrm{~g}$, respectively. Therefore, the seismic waves with these four peak accelerations were selected for the shaking table tests. The loading conditions of the tests are given in Table 1. 
To reveal the strain distribution of piles in saturated sandy foundation, comparative shaking table tests were conducted on piles in dry sand before the tests on saturated sand. For the lack of space, the details of these comparative tests are not mentioned here.

During the shaking table tests on saturated sandy foundation, a small soil-pile reaction was discovered under the seismic excitation with small peak acceleration. When the seismic excitation of $0.22 \mathrm{~g}$ was applied, the ground surface and the pile had relatively strong vibrations (Figure 3(a)). The surface and pile vibrations became obvious, as the peak acceleration reached $0.4 \mathrm{~g}$. In this case, sand ejection and water spraying were observed, indicating that the sandy soil suffers intense liquefaction (Figure 3(b)). After each test, the pore pressure was fully dissipated before implementing the next test.

Table 1. The loading conditions of shaking table tests

\begin{tabular}{c|c|c|c}
\hline $\begin{array}{c}\text { Serial } \\
\text { number }\end{array}$ & $\begin{array}{c}\text { Loading } \\
\text { conditions }\end{array}$ & $\begin{array}{c}\text { Peak } \\
\text { accelerations }\end{array}$ & Remarks \\
\hline 1 & TF-01 & $0.035 \mathrm{~g}$ & Magnitude 7 \\
2 & El-01 & $0.035 \mathrm{~g}$ & frequent earthquake \\
3 & TF-02 & $0.1 \mathrm{~g}$ & Magnitude 7 design \\
4 & El-02 & $0.1 \mathrm{~g}$ & earthquake \\
5 & $\mathrm{TF}-04$ & $0.22 \mathrm{~g}$ & Magnitude 7 rate \\
6 & El-04 & $0.22 \mathrm{~g}$ & earthquake \\
7 & $\mathrm{TF}-05$ & $0.4 \mathrm{~g}$ & Magnitude 8 rate \\
8 & $\mathrm{El-05}$ & $0.4 \mathrm{~g}$ & earthquake \\
\hline
\end{tabular}
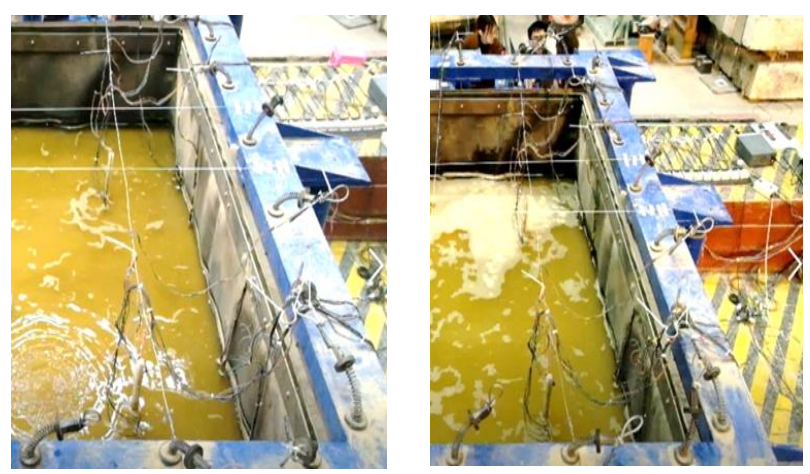

(a) Test with peak acceleration of $0.22 \mathrm{~g}$; (b) Test with peak acceleration of $0.4 \mathrm{~g}$

Figure 3. The macro vibration phenomena of saturated sandy foundation

\section{PORE PRESSURE IN SATURATED SANDY FOUNDATION}

The seismic response of the structure may vary greatly with input seismic waves. Under different seismic waves, the pore pressure ratios of the soil around FP-0 were measured at three different depths: $150 \mathrm{~mm}, 400 \mathrm{~mm}$, and $650 \mathrm{~mm}$. The time histories of the pore pressure ratios at the depths of $150 \mathrm{~mm}$ and $450 \mathrm{~mm}$ are displayed in Figures 4 and 5, respectively. Note that the measured data were treated with a $0.5-2 \mathrm{~Hz}$ lowpass filter, aiming to remove the fluctuating components.

As shown in Figure 4, at the depth of $150 \mathrm{~mm}$, the pore pressure ratios under two different seismic waves exhibited similar trends, when soil liquefaction occurred. Under either wave, the pore pressure ratio went through four stages: First, the pore pressure ratio did not change severely until 10s;
Second, the pore pressure ratio surged up to around 1 in the next 10s; Third, the pore pressure ratio remained stable till about 30s; Fourth, the pore pressure ratio gradually decreased to around $70 \mathrm{~s}$.

As shown in Figure 5, a similar four-stage trend was observed from the pore pressure ratios under two different seismic waves at the depth of $650 \mathrm{~mm}$. Comparatively, the pore pressure ratio at the depth of $150 \mathrm{~mm}$ was greater than that at $650 \mathrm{~mm}$. Hence, the pore pressure ratio is negatively correlated with soil depth.

To clarify the pore pressure from soil-pile interaction, the data collected by the pressure gauges $40 \mathrm{~mm}$ away from the pile under the El Centro wave were compared. The time history of pore pressure ratio at the occurrence of soil liquefaction is presented in Figure 6. It can be seen that the sandy soil at different positions was liquefied almost simultaneously. It is hard to tell which part of the sandy foundation was liquefied first. Besides, the pore pressure ratio decreased earlier from the lower depth of $650 \mathrm{~mm}$, and later, from $400 \mathrm{~mm}$.

Figure 7 shows the time history of pore pressure ratio at the depth of $400 \mathrm{~mm}$ under El Centro waves with different peak accelerations: $0.4 \mathrm{~g}$ and $0.22 \mathrm{~g}$. It can be found that, as the peak acceleration increased to $0.22 \mathrm{~g}$, the growth rate of pore pressure ratio rose slowly and peaked below 1.0, indicating that the sandy foundation is slightly liquefied. Moreover, the growth rate of pore pressure ratio (stage 2) under $0.4 \mathrm{~g}$ is greater than that under $0.22 \mathrm{~g}$.

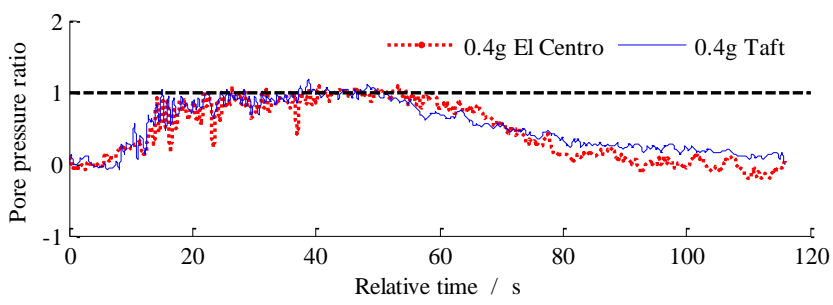

Figure 4. The time history of pore pressure ratio at the depth of $150 \mathrm{~mm}$ depth under two different seismic waves

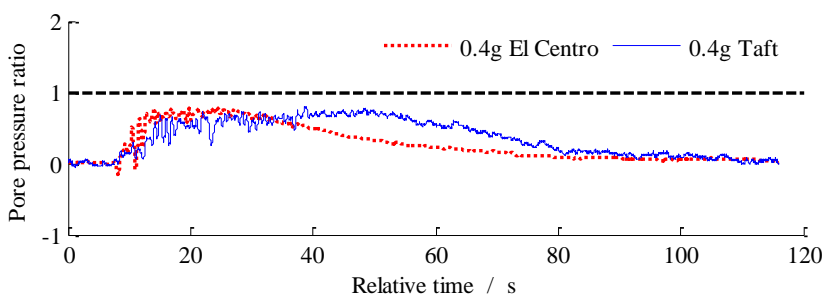

Figure 5. The time history of pore pressure ratio at the depth of $650 \mathrm{~mm}$ depth under two different seismic waves

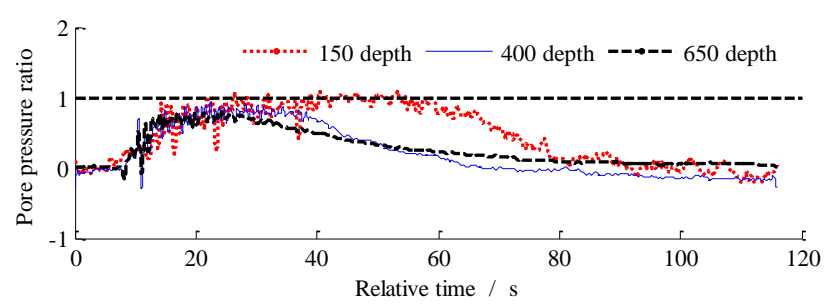

Figure 6. The time history of pore pressure ratio at $40 \mathrm{~mm}$ horizontal distance 


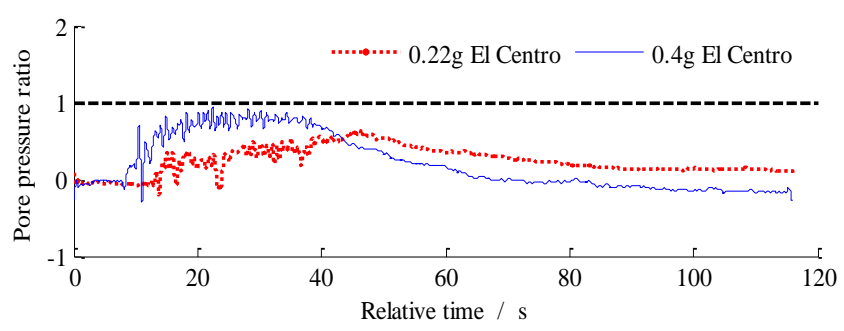

Figure 7. The time history of pore pressure ratio at the depth of $400 \mathrm{~mm}$ under El Centro waves with $0.4 \mathrm{~g}$ and $0.22 \mathrm{~g}$

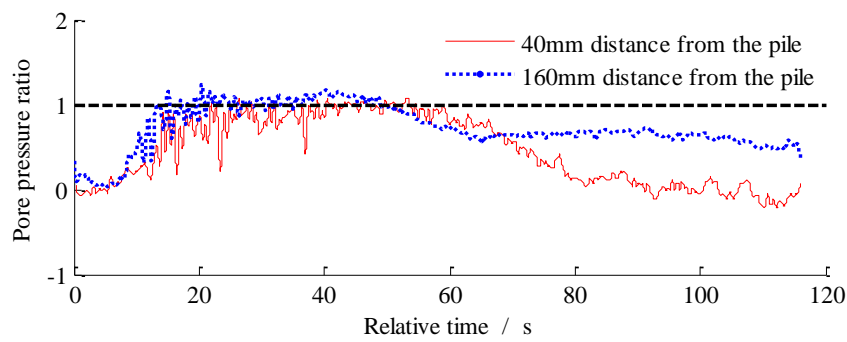

Figure 8. The time history of pore pressure ratio with different distances from the pile at the depth of $150 \mathrm{~mm}$

Furthermore, Figure 8 displays the time history of pore pressure ratio obtained from the data of gauges $40 \mathrm{~mm}$ and $160 \mathrm{~mm}$ away from the pile, under the El Centro wave with $0.4 \mathrm{~g}$ and at the same vertical depth $(150 \mathrm{~mm})$. It can be observed that the pore pressures with different distances from the pile were slightly different. The pore pressure ratio (stage 3 ) with the distance of $160 \mathrm{~mm}$ was a bit greater than that with $40 \mathrm{~mm}$. During the decline of pore pressure (stage 4), the pore pressure ratio with the distance of $160 \mathrm{~mm}$ was greater than that with $40 \mathrm{~mm}$. This means the horizontal distance from the pile has a certain effect on the pore pressure. Due to the existence of pile foundation, the pore pressure far away from the pile is larger than that near the pile at the same depth. After the decline of pore pressure, the pore pressure at the measuring point far from the pile is still very high.

\section{ACCELERATION RESPONSE OF SATURATED SANDY FOUNDATION}

\subsection{Time history of acceleration response}

In the saturated sandy foundation, the acceleration responses at different positions are partly affected by the features of the seismic wave. To identify the acceleration responses of saturated sandy foundation under different seismic waves, the acceleration responses at different depths under El Centro and Taft waves were tested, and plotted into Figures 9 and 10.

The acceleration response in each subgraph of Figure 9 was compared with that in the corresponding subgraph of Figure 10. The comparison shows that the acceleration response of the saturated sandy foundation under El Centro wave was greater than that under Taft wave, owing to the different features of the two seismic waves. Besides, the vibration range of the peak acceleration decreased with the growing vertical depth. In addition, the accelerate responses under these two waves exhibited similar trends with depth change: the peak acceleration decreased with the growing vertical depth. Finally, the peak acceleration with the horizontal distance of $40 \mathrm{~mm}$ appeared more often than that with $160 \mathrm{~mm}$, indicating that the change of acceleration increases with the proximity to the pile.

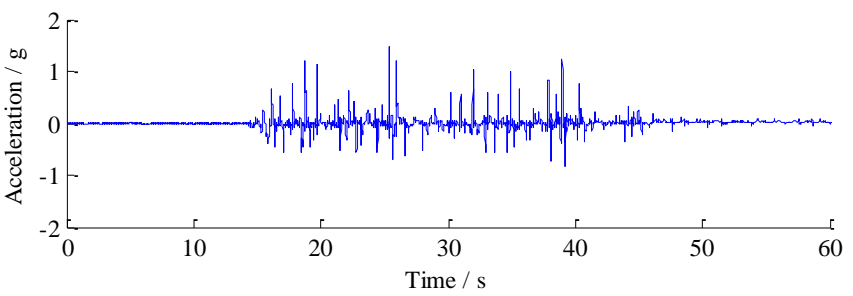

(a) Depth: 150mm; horizontal distance: $40 \mathrm{~mm}$

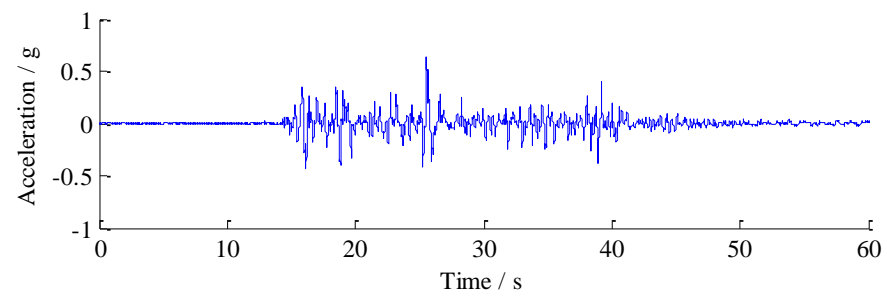

(c) Depth: 400mm; horizontal distance: $40 \mathrm{~mm}$

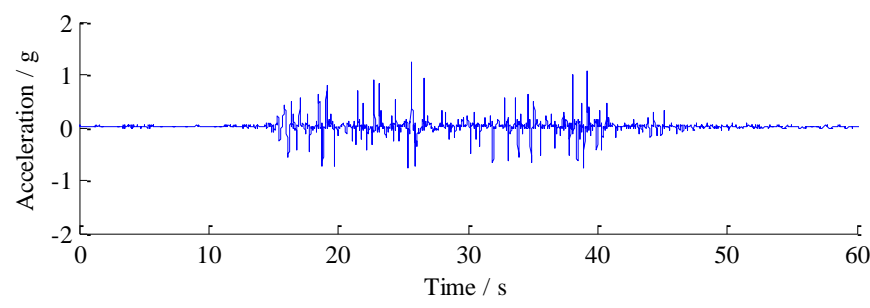

(b) Depth: 150mm; horizontal distance: $160 \mathrm{~mm}$

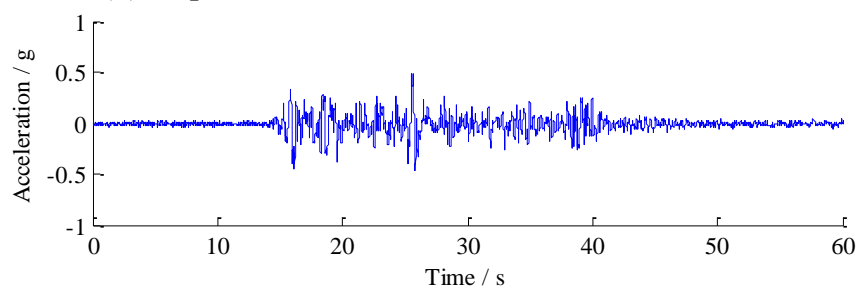

(d) Depth: 650mm; horizontal distance: $40 \mathrm{~mm}$

Figure 9. The time history of acceleration response of saturated sandy foundation under $0.4 \mathrm{~g}$ El Centro wave

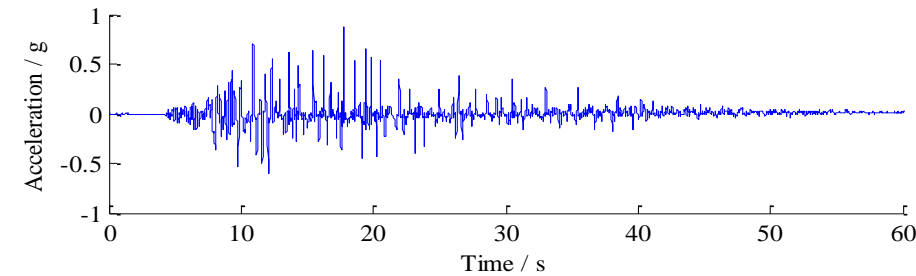

(a) Depth: $150 \mathrm{~mm}$; horizontal distance: $40 \mathrm{~mm}$

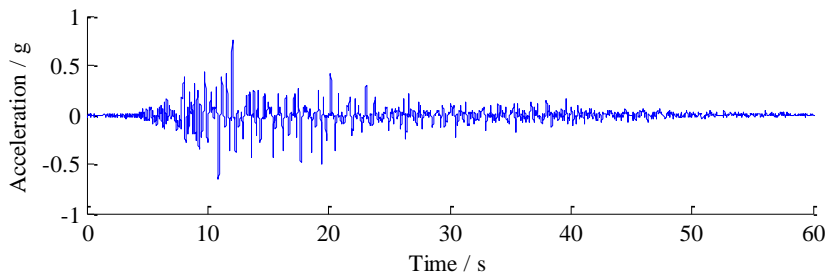

(b) Depth: 150mm; horizontal distance: $160 \mathrm{~mm}$ 


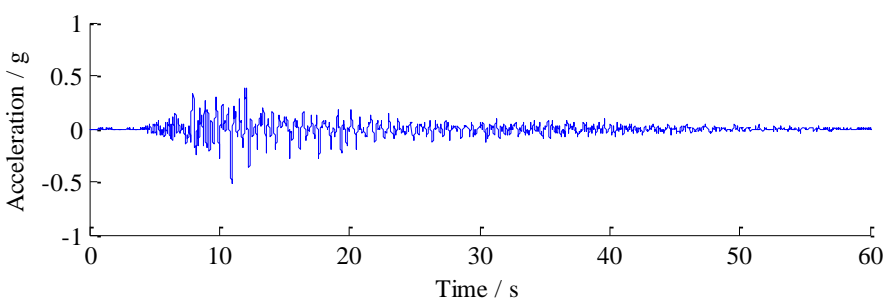

(c) Depth: 400mm; horizontal distance: $40 \mathrm{~mm}$

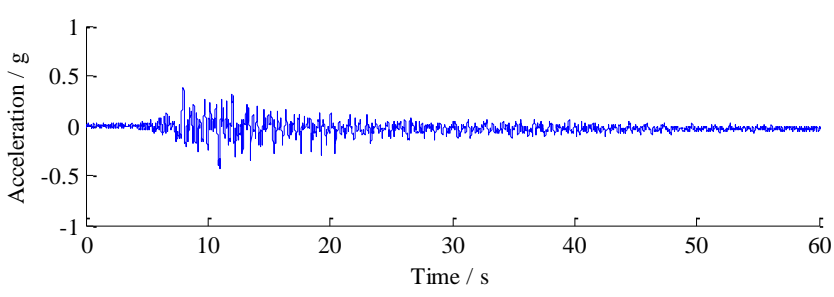

(d) Depth: $650 \mathrm{~mm}$; horizontal distance: $40 \mathrm{~mm}$

Figure 10. The time history of acceleration response of saturated sandy foundation under $0.4 \mathrm{~g}$ Taft wave

\subsection{Peak acceleration response and dynamic amplification factor}

The above test results show that El Centro wave has a greater impact on acceleration response of saturated sandy foundation than Taft wave. On this basis, shake table tests were carried out under El Centro waves with $0.1 \mathrm{~g}, 0.22 \mathrm{~g}$ and $0.4 \mathrm{~g}$. The three accelerations represent the magnitude 7 design earthquake, magnitude 7 rare earthquake, and magnitude 8 rare earthquake, respectively. The time history of peak acceleration responses at these accelerations are displayed in Figures 11-13.

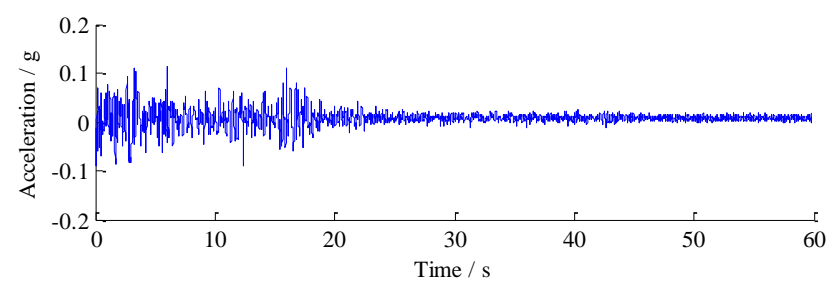

(a) $0.1 \mathrm{~g}$

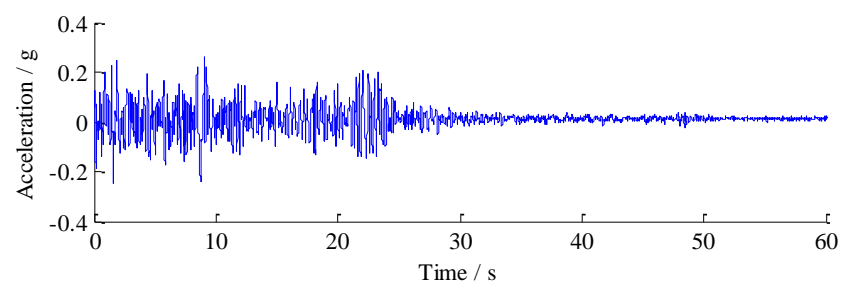

(b) $0.22 \mathrm{~g}$

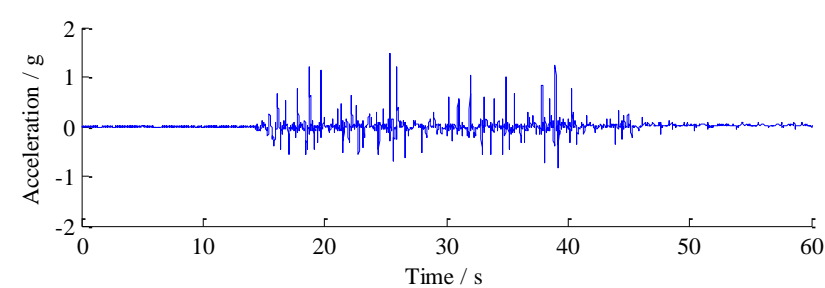

(c) $0.4 \mathrm{~g}$

Figure 11. The time history of acceleration response at the depths of $150 \mathrm{~mm}$ and $40 \mathrm{~mm}$ under El Centro wave with different accelerations

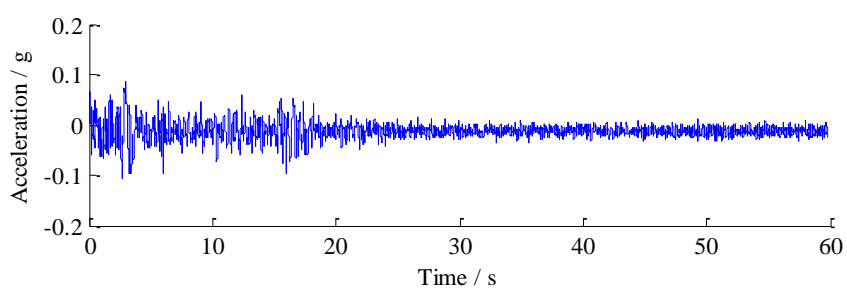

(a) $0.1 \mathrm{~g}$

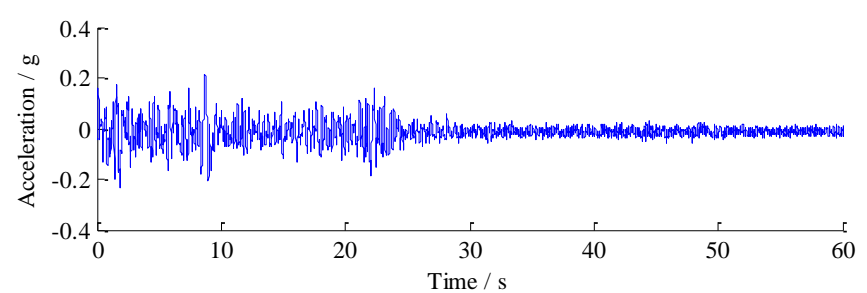

(b) $0.22 \mathrm{~g}$

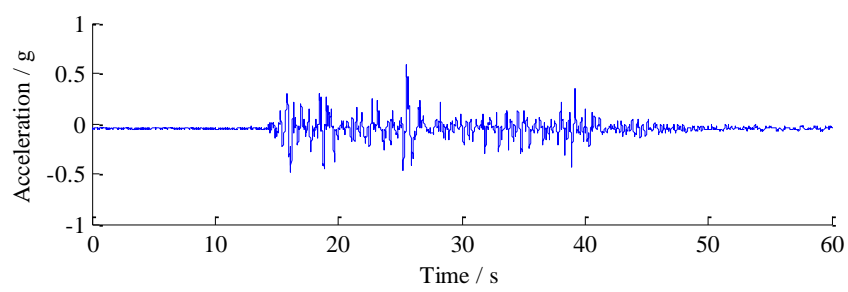

(c) $0.4 \mathrm{~g}$

Figure 12. The time history of acceleration response at the depths of $400 \mathrm{~mm}$ and $40 \mathrm{~mm}$ under El Centro wave with different accelerations

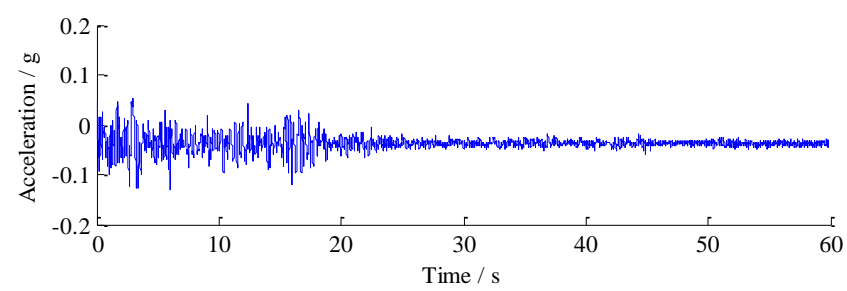

(a) $0.1 \mathrm{~g}$

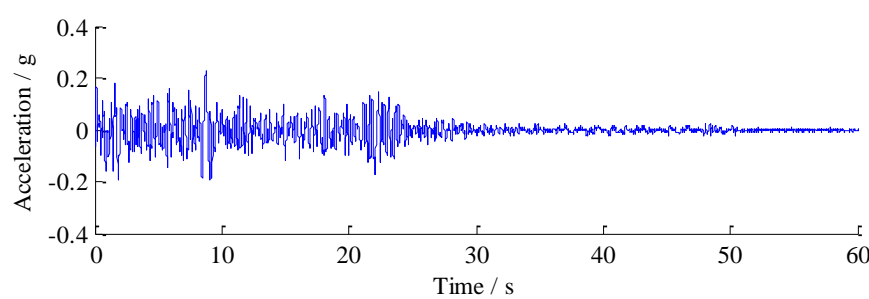

(b) $0.22 \mathrm{~g}$

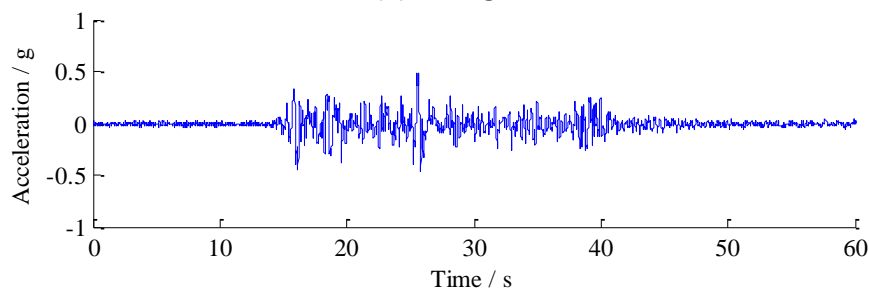

(c) $0.4 \mathrm{~g}$

Figure 13. The time history of acceleration response at the depths of $650 \mathrm{~mm}$ and $40 \mathrm{~mm}$ under El Centro wave with different accelerations 


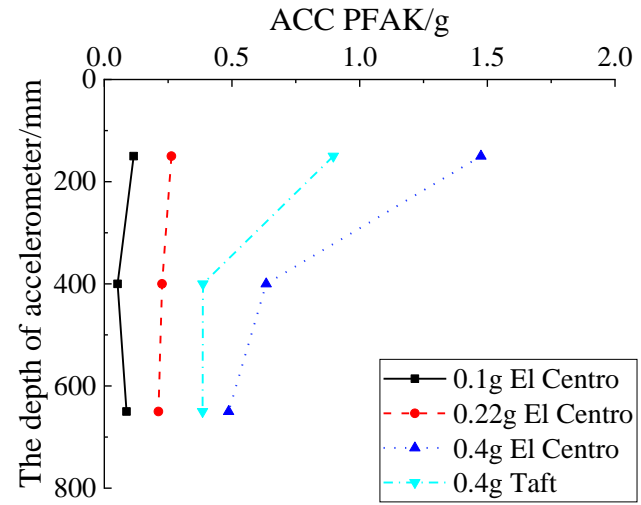

(a) Peak acceleration distribution

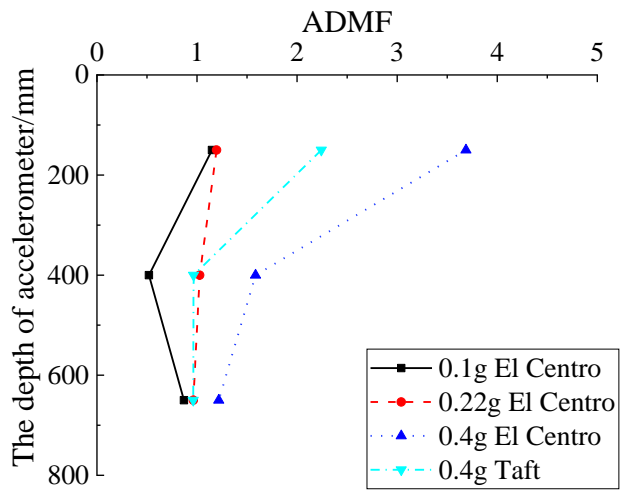

(b) Dynamic amplification factor

Figure 14. The distribution of peak acceleration along the depth of saturated sandy foundation

The peak acceleration responses of the saturated sandy foundation could be determined along the depth under the El Centro wave with different accelerations, according to Figures 11-13. Then, the peak accelerations under El Centro and Taft waves with different accelerations are summed up in Figure 14(a). Meanwhile, Figure 14(b) provides the trend of dynamic magnification factor, the ratio of peak acceleration response of the foundation to the peak acceleration of seismic wave, along the depth under the two kinds of waves with different accelerations.

As shown in Figure 14(a), the acceleration response of the sandy foundation increased with the peak acceleration of El Centro or Taft wave. The acceleration response of the upper soil around the pile was more intense than that of the lower soil. To be more specific, at the depth of $150 \mathrm{~mm}$, the smallest acceleration was observed under $0.1 \mathrm{~g}$ El Centro wave, and the greatest acceleration was discovered under $0.4 \mathrm{~g}$ El Centro

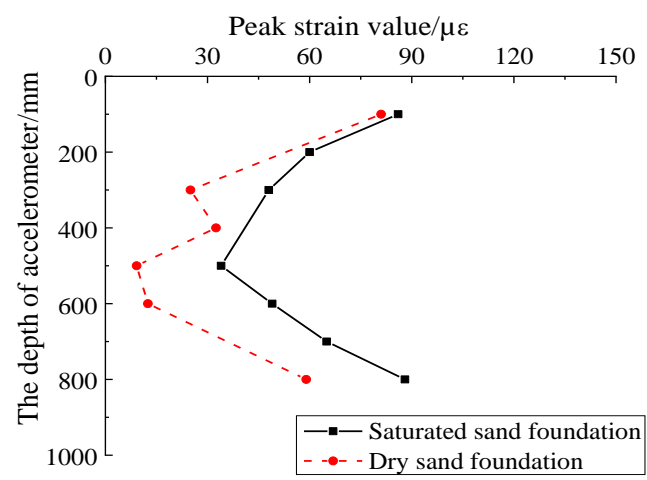

(a) $0.035 \mathrm{~g}$

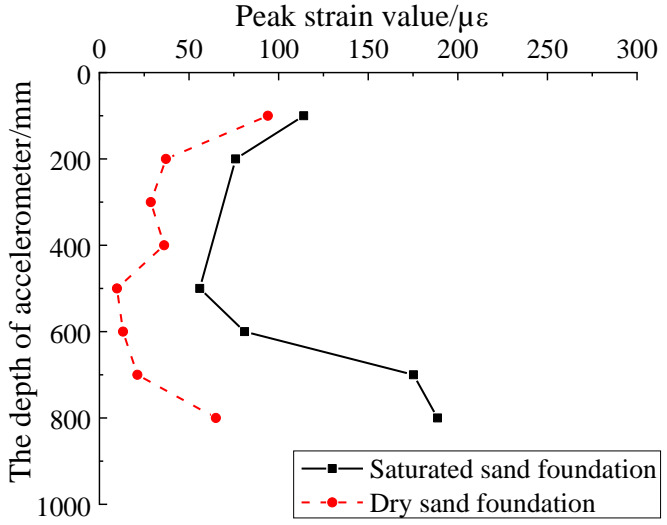

(c) $0.22 \mathrm{~g}$ wave. The maximum acceleration always appeared on the top at any acceleration.

As shown in Figure 14 (b), the dynamic magnification factor peaked at 1.150,1.195, and 3.687 at the depth of $150 \mathrm{~mm}$, corresponding to the peak accelerations of $0.1 \mathrm{~g}, 0.22 \mathrm{~g}$, and $0.4 \mathrm{~g}$, respectively. Hence, the maximum magnification factor occurs at the top of the sandy foundation. In addition, under the Taft wave, the distribution of the dynamic magnification factor around the pile is basically the same as that under the El Centro wave. However, when the peak acceleration was $0.4 \mathrm{~g}$, the dynamic amplification factor along the pile depth under Taft wave was greater than that of El Centro wave at the same depth.

\section{STRAIN DISTRIBUTION OF FRICTION PILE UNDER DIFFERENT FOUNDATION CONDITIONS}

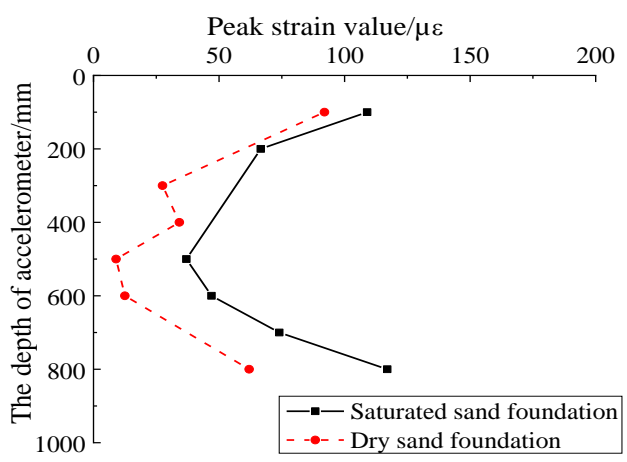

(b) $0.1 \mathrm{~g}$

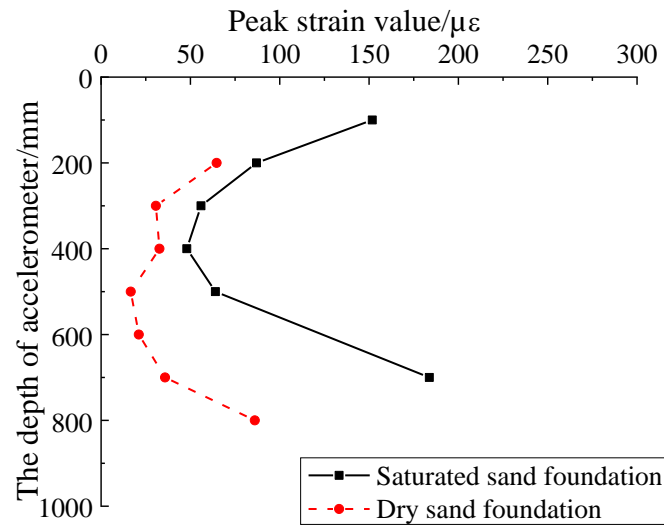

(d) $0.4 \mathrm{~g}$

Figure 15. The comparison of peak strains of FP-1 under El Centro waves with different accelerations 


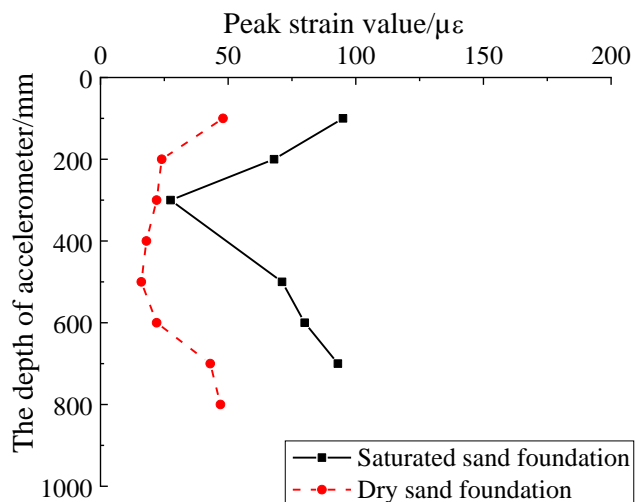

(a) $0.035 \mathrm{~g}$

Peak strain value/ $\mu \varepsilon$

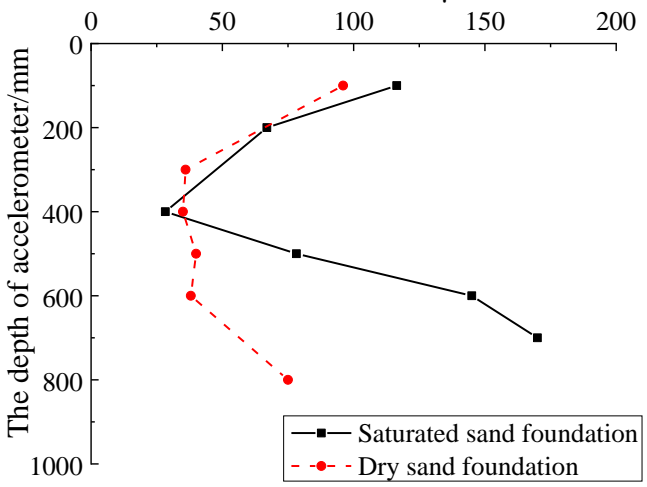

(c) $0.22 \mathrm{~g}$

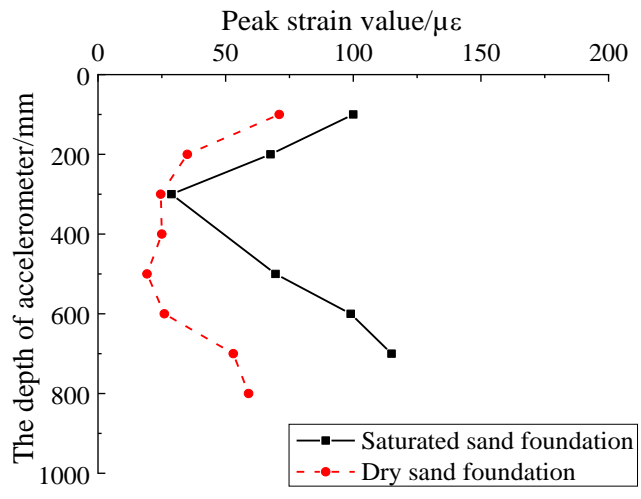

(b) $0.1 \mathrm{~g}$

Peak strain value/ $\mu \varepsilon$

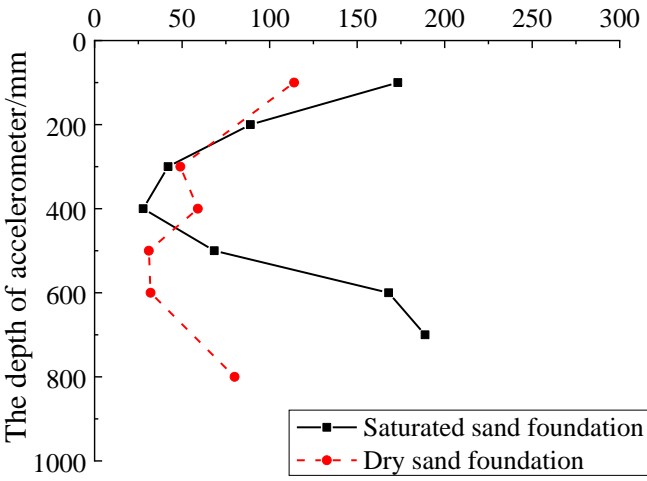

(d) $0.4 \mathrm{~g}$

Figure 16. The comparison of peak strains of FP-1 under Taft waves with different accelerations

Both dry sand and saturated sand were compared through shaking table tests. According to the time history of strains measured by the strain gauges, the peak strain responses along FP-1 under El Centro wave with $0.1 \mathrm{~g}, 0.22 \mathrm{~g}$, and $0.4 \mathrm{~g}$ were determined.

As shown in Figure 15, the distribution of peak strain of dry sand is similar to that of saturated sand: the peak strain decreased from top to a certain depth, and then increased with the depth. The minimum peak strain was observed. What is more, the peak strain of saturated sand was greater than that of the dry sand under different seismic accelerations (Figures 15(a)-(d)). Therefore, the friction pile surrounded by saturated sand is subject to greater strain than that surrounded by dry sand.

Next, shaking table tests were performed on dry and saturated sands under the Taft waves with four peak accelerations: $0.035 \mathrm{~g}, 0.1 \mathrm{~g}, 0.22 \mathrm{~g}$ and $0.4 \mathrm{~g}$. Figure 16 records the peak strains along the TP-1 obtained through the tests. Overall, the strain responses of the friction pile under the Taft waves in dry and saturated sands are similar to those under the El Centro waves.

As shown in Figure 16, the peak strains at the two ends of the pile were greater than the peak strain at the middle of the pile. Under the Taft waves, the peak strain of the pile surrounded by saturated sand was not always larger than that of the pile surrounded by dry sand. For instance, the peak strains on the pile surrounded by dry sand were greater than those on the pile surrounded by saturated sand at the depth of $400 \mathrm{~mm}$. In other words, the peak strain of the friction pile in the dry sand is sometimes greater than that in saturated sand. Further research is needed to better illustrate the phenomenon. Importantly, Figures 15 and 16 demonstrate that, under both El Centro and Taft waves, the peak strain response decreased to a certain depth and then increased with the depth. This indicates the peak strain distribution is not greatly affected by soil liquefaction induced by earthquake.

\section{CONCLUSIONS}

This paper carries out shaking table tests on friction piles surrounded by dry and saturated sandy foundation, separately, and simulates the seismic excitation of El Centro and Taft waves on the sandy foundation with a suspended laminar shear box. Through the tests, the authors investigated the dynamic features of the sandy foundation, including but not limited to pore pressure ratio and acceleration response. The main conclusions are as follows:

(1) Under seismic action, the trend of pore pressure of the soil around the pile is basically the same at different depths. The pore pressure of the saturated sandy soil around the pile firstly rockets up, then remain constant, and later enters a slow decline; the decline of pore pressure ratio starts earlier from the lower depth. In addition, the horizontal distance from the pile has a certain effect on the pore pressure.

(2) Under seismic action, the acceleration response of saturated sandy foundation varies with the features of the seismic wave. The peak acceleration of saturated sand is negatively correlated with the vertical depth. Besides, the change of acceleration of saturated sand increases with the proximity to the pile.

(3) Under El Centro or Taft wave, the acceleration response of the foundation increases with the peak acceleration; the acceleration response of the upper soil around the pile is obviously more intense than that of the lower soil.

(4) Under the conditions of dry sand and saturated sand, the 
strain of friction pile is smaller in the middle and greater at both ends, peaking at the pile end. Under El Centro wave, the peak strain for the saturated sand is greater than that for the dry sand at different accelerations; Under Taft wave, the peak strain on the pile in the dry sand is sometimes greater than that in saturated sand. Overall, the friction pile suffers greater strain when it is surrounded by saturated sand rather than dry sand.

\section{ACKNOWLEDGMENTS}

The authors would like to thank the following projects and organizations for their support and sponsorship with this paper: Project of Science and Technology Plan for Housing and Urban-Rural Construction of Shandong Province (Grant No.: 2017-K2-004), Project of the Coordination and Innovation Center of Disaster Prevention and Mitigation of Civil Structures of Institutions of Higher Education of Shandong Province (Grant No.: XTP201912), and Technological Innovation Projects of Shandong Luqiao Group.

\section{REFERENCES}

[1] Mizuno, H., Iiba, M., Hirade, T. (1996). Pile damage during the 1995 Hyogoken-Nanbu earthquake in Japan. In Proceedings of the 11th World Conference on Earthquake Engineering, 977: Acapulco, Mexico: [sn].

[2] Kagawa, T., Minowa, C., Abe, A. (2000). EDUS project (earthquake damage to underground structures). In 12WCEE. Auckland: IAEE.

[3] Hamada, H., Yasuda, S., Isoyama, R., Emoto K. (1986). Study on liquefaction induced permanent ground displacements. Research report, Association for the development of Earthquake Prediction, Japan, 1-87.

[4] Hamada, M., O'Rourke, T.D. (1992). Case studies of liquefaction and lifeline performance during past earthquakes, Vol. 1: Japanese case studies. Technical Report, NCEER-92-0001, National Center for Earthquake Engineering Research, university at Buffalo, 430.

[5] Tokimatsu, K., Asaka, Y. (1998). Effect of liquefactioninduced ground displacements o pile performance in the 1995 Hyogoken-Nambu earthquake. Special Issue of Soils and Foundations, 38(Supplement): 163-177. https://doi.org/10.3208/sandf.38.Special_163

[6] Motamed, R., Towhata, I., Honda, T., Yasuda, S., Tabata, K., Nakazawa, H. (2009). Behavior of pile group behind a sheet pile quay wall subjected to liquefaction-induced large ground deformation observed in shaking test in EDefense project. Soils and Foundations, 49(3): 459-476. https://doi.org/10.3208/sandf.49.459

[7] Orense, R., Ishihara, K., Yasuda, S., Morimoto, I. and Takagi, M. (2000). Soil spring constants during lateral flow of liquefied ground. Proc. $12^{\text {th }}$ World Conference on Earthquake Engineering New Zealand.

[8] Tokimatsu, K., Suzuki, H. (2004). Pore water pressure response around pile and its effects on $\mathrm{p}-\mathrm{y}$ behavior during soil liquefaction. Soils and Foundations, 44(6): 101-110. https://doi.org/10.3208/sandf.44.6_101

[9] Yao, S., Kobayashi, K., Yoshida, N., Matsuo, H. (2004). Interactive behavior of soil-pile-superstructure system in transient state to liquefaction by means of large shake table tests. Soil Dynamics and Earthquake Engineering, 24(5): 397-409. tps://doi.org/10.1016/j.soildyn.2003.12.003

[10] Shirato, M., Nonomura, Y., Fukui, J., Nakatani, S. (2008). Large-scale shake table experiment and numerical simulation on the nonlinear behavior of pile-groups subjected to large-scale earthquakes. Soils and Foundations, $\quad$ 48(3): 375-396. https://doi.org/10.3208/sandf.48.375

[11] Tokimatsu, K., Suzuki, H., Tabata, K., Sato, M. (2007). Three-dimensional shaking table tests on soil-pilestructure models using E-defense facility. In Proceedings of $4^{\text {th }}$ International Conference on Earthquake Engineering, June 25-28, Thissaloniki, Greece.

[12] Abdoun, T., Dobry, R., O'Rourke, T.D, Goh, S.H. (2013). Pile response to lateral spreads: centrifuge modeling. Journal of Geotechnical and Geoenvironmental Engineering, ASCE, 129(10): 869-878.

[13] Imamura, S., Hagiwara, T., Tsukamoto, Y., Ishihara, K. (2004). Response of pile groups against seismically induced lateral flow in centrifuge model tests. Soils and Foundations, $\quad$ 44(3): 39-55. https://doi.org/10.3208/sandf.44.3_39

[14] McVay, M., Zhang, L., Molnit, T., Lai, P. (1998). Centrifuge testing of large laterally loaded pile groups in sands. Journal of Geotehnical and Geoenvironmental Engineering, ASCE, 124(10): 1016-1026.

[15] Motamed, R., Sesov, V., Towhata, I., Anh, N.T. (2010). Experimental modeling of large pile groups in sloping ground subjected to liquefaction-induced lateral flow: 1G shaking table tests. Soils and Foundations, 50(2): 261279.

[16] Chopra, A.K., Chakrabarty, P., Dasgupta, G. (1976). Dynamic stiffness matrices for viscoelastic half-plane foundations. Journal of the Engineering Mechanics Division, ASCE, 102(3): 497-514.

[17] Toki, K., Sato, T. (1997). Seismic response analysis of surface layer with irregular boundaries. In proceedings, $6^{\text {th }}$ world conference on Earthquake Engineering, New Delhi, India, January, 409-415.

[18] Lu, X.L., Li, P.Z., Chen, B., Chen, Y.Q. (2005). Computer simulation of the dynamic layered soil pile structure interaction system. Canadian Geotechnical Journal, 42(3): 742-751. https://doi.org/10.1139/t05-016

[19] Chau, K.T., Shen, C.Y., Guo, X. (2009). Nonlinear seismic soil-pile-structure interactions: shaking table tests and FEM analyses. Soil Dynamics and Earthquake Engineering, 29(2): https://doi.org/10.1016/j.soildyn.2008.02.004

[20] Kang, H.R., Zhang, X.D., Li, H. (2009). The bearing character of bridge piles in karst areas. Ninth International Conference of Chinese Transportation Professionals https://doi.org/10.1061/41064(358)7 